\title{
Pore water conditions drive calcium carbonate dissolution in reef sands
}

\author{
A J KESSLER ${ }^{1 *}$, A ROGERS ${ }^{2}$, T CYRONAK ${ }^{3}$, M F \\ BOURKE ${ }^{2}$, H HASLER-SHEETAL ${ }^{4}, \mathrm{R} \mathrm{N} \mathrm{GLUD}^{4}, \mathrm{C}$ \\ GREENING $^{5}$, F J R MEYSMAN ${ }^{6}$, B D EYRE ${ }^{7}$, P L M COOK ${ }^{2}$ \\ ${ }^{1}$ School of Earth, Atmosphere \& Environment, Monash \\ University, * adam.kessler@monash.edu \\ ${ }^{2}$ School of Chemistry, Monash University \\ ${ }^{3}$ Scripps Institution of Oceanography \\ ${ }^{4}$ Department of Biology, University of Southern Denmark \\ ${ }^{5}$ School of Biological Sciences, Monash University \\ ${ }^{6}$ Department of Biology, University of Antwerp \\ ${ }^{7}$ Centre for Coastal Biogeochemistry, Southern Cross \\ University
}

Permeable calcium carbonate reef sands are are predicted to become net dissolving in the next 20-50 years [1], but the factors that control this dissolution remain poorly understood. In situ experiments suggest that reefs become net dissolving when the the aragonite saturation state $\left(\Omega_{\mathrm{a}}\right)$ in sea water falls below $\sim 3$ (e.g. [2]), indicating that pore water processes are an integral factor in controlling dissolution.

To better understand the dissolution of reef sands at the pore water scale, we used flow-through reactors to measure dissolution with varied $\Omega_{\mathrm{a}}$, grain size and oxygen availablilty. The sediment became net dissolving at $\Omega_{\mathrm{a}} \sim 2$, suggesting that the bulk pore water is still not representative of conditions at the site of dissolution, and that dissolution likely occurs in microniches inside porous sand grains $[3,4]$.

Unexpectedly, dissolution rates appeared to be faster under oxic conditions. This appears to be caused by the dominance of fermentation over classical anaerobic respiration (e.g. sulfide reduction) under anoxic conditions, as previously observed in silica sands [5]. The occurrence of fermentation may mean that rates of dissolution in reef sands are underestimated.

[1] Eyre et al. (2014) Nature Climate Change 4, 969-976. [2] Cyronak et al. (2013) Geophysical Research Letters 40, 4876-4881. [3] Kessler et al., (2014) Geochimica et Cosmochimica Acta 141, 440-453. [4] Cook et al. (2017) Biogeosciences 14, 4061-4069. [5] Kessler et al. (2019) Nature Microbiology 4, 1014-1023. 